\title{
Characterization of the microbial community structure in Candidatus Liberibacter asiaticus-infected citrus plants treated with antibiotics in the field
}

\author{
Muqing Zhang ${ }^{1,2,3}$, Charles A Powell ${ }^{1}$, Ying Guo ${ }^{1}$, Lesley Benyon ${ }^{2}$ and Yongping Duan ${ }^{2^{*}}$
}

\begin{abstract}
Background: Huanglongbing (HLB) is a worldwide devastating disease of citrus. There are no effective control measures for this newly emerging but century-old disease. Previously, we reported a combination of Penicillin $G$ and Streptomycin was effective in eliminating or suppressing the associated bacterium, 'Candidatus Liberibacter asiaticus' (Las).

Results: Here we report the bacterial composition and community structure in HLB-affected citrus plants during a growing season and while being treated with antibiotic combinations PS (Penicillin G and Streptomycin) and KO (Kasugamycin and Oxytetracycline) using the Phylochip ${ }^{\mathrm{TM}} \mathrm{G} 3$ array. Both antibiotic treatments resulted in significantly lower Las bacterial titers $(\operatorname{Pr}<0.05)$ and hybridization scores. Of the 50,000+ available operational taxonomic units (OTUs) on PhyloChip ${ }^{\mathrm{TM}} \mathrm{G} 3,7,028$ known OTUs were present in citrus leaf midribs. These OTUs were from 58 phyla, of which five contained 100 or more OTUs, Proteobacteria (44.1\%), Firmicutes (23.5\%), Actinobacteria (12.4\%), Bacteroidetes (6.6\%) and Cyanobacteria (3.2\%). In the antibiotic treated samples, the number of OTUs decreased to a total of 5,599. The over-all bacterial diversity decreased with the antibiotic treatments, as did the abundance of 11 OTUs within Proteobacteria, Firmicutes, Bacteroidetes and Planctomycetes. Within the Proteobacteria, ten OTUs representing the class $\gamma$-proteobacteria increased in abundance after four months of treatment, when the Las bacterium was at its lowest level in the HLB-affected citrus field plants.
\end{abstract}

Conclusions: Our data revealed that Proteobacteria was constantly the dominant bacterial phylum recovered from citrus leaf midribs, with the a-proteobacterial and the $\gamma$-proteobacterial classes vying for prevalence. In addition, the level of bacterial diversity found in the leaf midribs of field citrus was greater than previously described. Bacterial cells in close proximity may be able to modify their microenvironment, making the composition of the microbial community an important factor in the ability of Las to cause HLB progression. A low Las level was seen as an annual fluctuation, part of the bacterial population dynamics, and as a response to the antibiotic treatments.

\section{Background}

Huanglongbing (HLB) is one of the most serious diseases of citrus and causes great losses in the citrus industry worldwide. It has been reported that since 2006, HLB has cost Florida's economy an estimated $\$ 3.63$ billion in lost revenues and 6,611 jobs by reducing orange juice production [1]. HLB is associated with three species of fastidious and phloem-limited $\alpha$-proteobacteria in the genus

\footnotetext{
* Correspondence: yongping.duan@ars.usda.gov

${ }^{2}$ USDA-ARS, US Horticultural Lab, Fort Pierce, FL 34945, USA

Full list of author information is available at the end of the article
}

'Candidatus Liberibacter': 'Ca. Liberibacter asiaticus' (Las), ' $\mathrm{C} a$. Liberibacter africanus', and ' $\mathrm{Ca}$. Liberibacter americanus' [2], of which Las is the only species in the USA. Although HLB resistant citrus varieties are being developed to combat the disease, it will likely take over 10 years to produce and evaluate these resistant varieties in Florida [3]. Since Florida citrus trees are already infected, it is essential to develop an efficient treatment to combat HLB in the interim. Development of a bactericide or other therapeutic compound would provide an additional tool for the control of HLB.

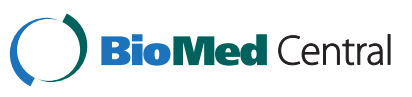


The microbial communities of leaves are diverse and bacteria, of many genera, are the most abundant inhabitants. It is thought that cell density-dependent signaling may play a role in epiphytic bacterial behavior and that cell-cell signaling may influence bacterial fitness [4]. Thus, bacterial cells within aggregates or in close proximity may be able to modify their microenvironment by triggering neighboring bacteria to express traits for their benefit. Therefore, the composition of the microbial community may be important for the ability of Las to cause HLB progression. Certain citrus plants within heavily Lasinfected groves appear to "escape" the disease and remain healthy. It has been hypothesized that these plants, which share a similar growing environment, may have a unique microbial composition [5], indicating that the microbial community in citrus may play a key role in the development of HLB. Few reports have described the composition of the bacterial community associated with citrus [5,6], the effects of the season, or the impact of antibiotic treatments on the microbial communities in planta. Thus, the dynamics of the citrus bacterial population are not well characterized.

The introduction of antibiotics for the treatment of bacterial diseases revolutionized human medicine. Since then, plant pathologists have been interested in their efficacy for controlling plant bacterial diseases. Antibiotics have been used to control bacterial diseases of fruit trees and to limit contamination in micropropagation and plant tissue culturing for over 50 years [7-9]. Nearly 40 antibiotics have been tested for plant disease control but less than 10 have been used commercially and, of those, only streptomycin and tetracycline have had significant usage in fruit trees [10]. During the 1970s, tetracycline was evaluated by direct injection into the trunks of HLB-affected citrus trees in South Africa, China, and Indonesia [11-14]. However, this practice was discontinued due to labor costs and phytotoxicity. HLB has also previously been controlled by penicillin carbendazin $[15,16]$. In an earlier study [17], the combination of penicillin and streptomycin was found to be effective in eliminating or suppressing the Las bacterium, and the combination provided a therapeutically effective level of control for a much longer time than when either antibiotic was administered separately.

To increase the throughput of bacterial detection, $16 \mathrm{~S}$ rRNA gene-based phylogenetic analysis has been commonly employed to characterize microbial diversity $[18,19]$. A high-density 16S rRNA gene oligonucleotide microarray, the PhyloChip ${ }^{\mathrm{Tm}}$, has recently been developed and effectively used to study bacterial population diversity. It is particularly adept at identifying bacteria in the environment [20], and a recent study on the bacterial diversity in HLBaffected citrus used the PhyloChip ${ }^{\text {тM }}$ G2 and 16S rRNA gene cloned libraries [5]. The updated PhyloChip ${ }^{\mathrm{Tm}}$ generation 3 (G3) includes 1.1 million probes, the inclusion of strain specific probe sets, the ability to detect over 50,000 operational taxonomic units (OTUs), and over 320,000 sequences in the reference database, which is over 10 times greater than that for the PhyloChip ${ }^{\text {rm }}$ G2 [21]. Here, we used the PhyloChip ${ }^{\text {Tm }}$ G3 array to explore the differences in the relative abundance and phylogenetic diversity of the bacterial communities associated with HLB-affected citrus plants in the field over a growing season and those treated with antibiotic combinations.

\section{Results}

\section{Dynamic variations of the bacterial community in HLB-affected field citrus}

The most prevalent bacterial phylum in citrus leaves in October 2010 was Proteobacteria with an average of 1,301 OTUs out of 2,948 OTUs (44.1\%). The next most prevalent phylums were the Firmicutes (566 of 2,948; $19.2 \%$ ) and the Actinobacteria (458 of 2,948; 15.5\%) (Additional file 1: Table S1). The number of OTUs in the Bacteriodetes decreased at a statistically significant level $(\operatorname{Pr}<0.05)$ between October 2010 and April 2011, and that difference appeared to be concentrated in the class of Flavobacteria. While the phylum Proteobacteria itself remained at $44 \%$ of the bacterial community, the number of OTUs in the $\alpha$-proteobacterial and $\beta$ proteobacterial classes decreased significantly $(\operatorname{Pr}<0.05)$. Among the $\alpha$-proteobacteria, the orders Rhizobiales $(P r<0.05)$ and Sphingomonadales $(P r<0.01)$ had decreased OTUs, and among the $\beta$-proteobacteria the order Burkholderiales had decreased OTUs $(\operatorname{Pr}<0.05)$. While the number of OTUs in the $\gamma$-proteobacteria as a class increased, they decreased in the order Pseudomonadales $(\operatorname{Pr}<0.05)$. The increase in the $\gamma$-proteobacterial class was statistically significant, and the difference appears concentrated in the Enterobacteriales $(P r<0.05)$. This was the only member of the bacterial community to show an increase in the number of OTUs in April 2011 over October 2010. The total OTUs for all phyla had dropped to $67 \%$ of the October 2010 level.

In the period from April 2011 to October 2011, many of the bacterial phyla that had a decrease in OTUs during the proceeding period began to recover. Actinobacteria, Firmicutes, and Spirochaetes all had increased numbers of OTUs, and as a percentage of total OTUs they had all surpassed their October 2010 levels. Proteobacteria was still the most abundant phylum but it represented only $39 \%$ of the total OTUs in October 2011. The $\beta$ proteobacterial class had significantly more OTUs $(P r<0.05)$ as did the order Burkholderiales $(\operatorname{Pr}<0.05)$. The number of OTUs in the $\gamma$-proteobacterial class decreased significantly $(P r<0.05)$, and this difference appears concentrated in the order Enterobacteriales $(P r<0.05)$. While the bacterial OTU levels appeared to be trending upward, by October of 2011 the overall 
abundance of bacteria was still only $72 \%$ of the October 2010 level.

\section{Las bacterium in HLB-affected citrus treated with antibiotic combinations}

The dynamic variations of Las bacterial titers from August 2010 to October 2011 at the USHRL farm, Fort Pierce, FL are presented in Figure 1. The results showed that the Las bacterial population fluctuated throughout the year in HLB-affected citrus plants with or without antibiotic treatments. The highest Las bacterial titers (lowest $\mathrm{Ct}$ values) were observed in December 2010, and the lowest Las bacterial titers (highest $\mathrm{Ct}$ values) were recorded in April 2011. This variation generally coincided with HLBsymptoms in the field. There were no significant differences among the antibiotic treatments and the water control before the initial applications in August 2010. Two months after the initial applications, significant differences $(P r<0.05)$ existed between the antibiotic treatments and the controls. By April 2011, the titers had decreased by more than 13-fold in the water control, 259-fold in the KO treated citrus and 97-fold in the PS treated citrus. The HybScore of OTU63806, which represented Candidatus Liberibacter from PhyloChip ${ }^{\mathrm{Tm}}$ G3, coincided with the Las bacterial titers detected by qPCR ( $\mathrm{r}=0.812)$. HybScores averaged 12,186 $\pm 1,320$ in the untreated trees (water control, CK) compared to $11,226 \pm 1,458$ and $11,037 \pm 678$ in the HLB-affected trees treated with KO and PS, respectively. HybScores were the lowest in April 2011 when the HLBbacterial population was also at its lowest level (Figure 2).

\section{Bacterial community structure and diversity}

The PhyloChip ${ }^{\text {тm }}$ G3 array was used to gain insights into the structural composition and diversity of bacteria in the

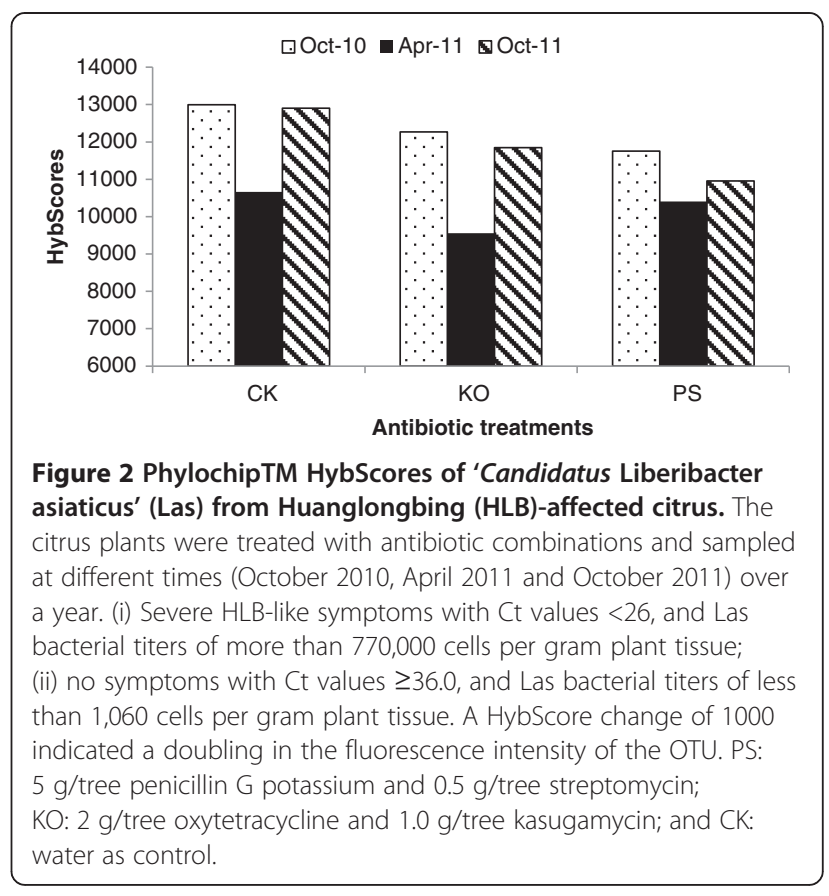

leaf midrib from HLB-affected citrus treated with antibiotic combinations (PS and KO). Of the 7,028 OTUs from our field citrus samples found on the PhyloChip ${ }^{\text {tw }}$ G3, a total of 5,599 (79.7\%) were detected in our antibiotic treated field samples. The number of OTUs found per treatment (PS, KO or CK) and sampling time point (October 2010, April 2011 or October 2011) ranged from 1,981 to 2,487 (Additional file 1: Table S1). In total, 58 phyla were detected, of which five phyla had 100 or more OTUs, Proteobacteria (3,099 proteobacterial OTUs out of 7,028 total OTUs, 44.1\%), Firmicutes (1,651 of 7,028 OTUs, 23.5\%), Actinobacteria (874 of 7,028 OTUs,

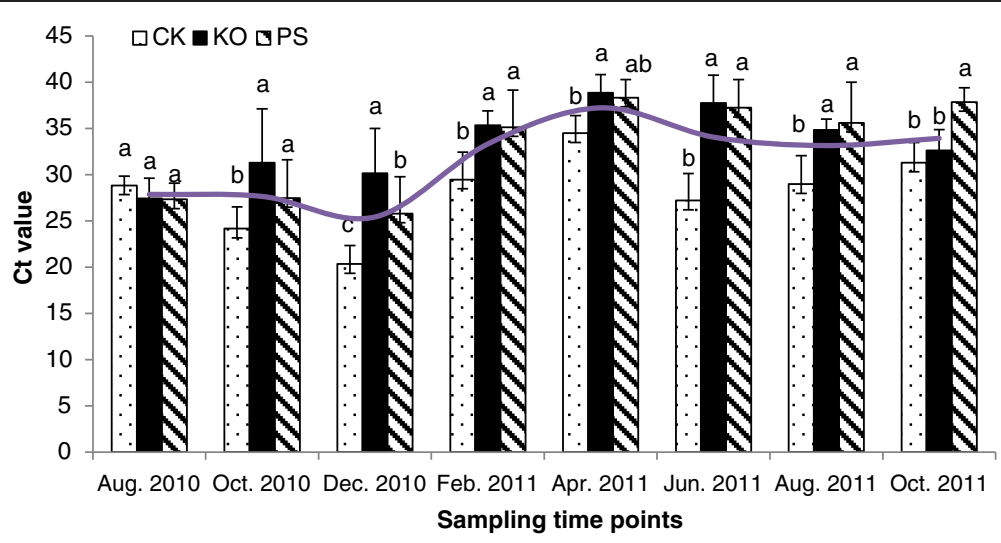

Figure 1 qPCR Ct values of 'Candidatus Liberibacter asiaticus' (Las) in Huanglongbing (HLB)-affected citrus treated with antibiotic combinations. The higher Ct values represent lower Las bacterial titers in the samples. (i) Severe HLB-like symptoms with Ct values $<26$, and Las bacterial titers of more than 770,000 cells per gram plant tissue, (ii) no symptoms with Ct values $\geq 36.0$, and Las bacterial titers of less than 1,060 cells per gram plant tissue. PS: $5 \mathrm{~g} /$ tree penicillin G potassium and $0.5 \mathrm{~g} /$ tree streptomycin; KO: $2 \mathrm{~g} /$ tree oxytetracycline and $1.0 \mathrm{~g} /$ tree kasugamycin; and CK: water as control. The different letters on the bars represent the significance at the $0.05 \%$ level $(\operatorname{Pr}<0.05)$. The smooth top line represents the seasonal fluctuation of the Las bacterium. 
12.4\%), Bacteroidetes (466 of 7,028 OTUs, 6.6\%) and Cyanobacteria (222 of 7,028 OTUs, 3.2\%). Proteobacteria were still dominant in the bacterial populations after treatments. In trees receiving the antibiotic combinations $\mathrm{KO}$ and PS, the average OTUs over sampling time points accounted for $44.5 \%$ and $44.2 \%$, respectively, of the treated populations, while they represented $38.9 \%$ of the control population. Proteobacteria were also dominant in the bacterial population at all sampling time points. The average OTUs in the antibiotic treatments accounted for $44.1 \%, 43.9 \%$ and $38.6 \%$ of the bacterial population in October 2010, April 2011, and October 2011, respectively. When compared to the bacterial populations in the leaves of trees receiving the water control treatment, the Bacteroidete population decreased $(\operatorname{Pr}<0.05)$ by $65.3 \%$ and $51.8 \%$ in the leaves of trees receiving the $\mathrm{KO}$ and PS treatments, respectively (Additional file 1 : Table S1).

The PhyloChip data indicated a change in the community profile over the sampling time points and showed fewer unique OTUs in populations subjected to antibiotic treatments (Additional file 1: Table S1; Figure 3A). The lowest number of OTUs was detected in April 2011 after the antibiotics had been applied four times (Additional file 1: Table S1). The phylum Bacteriodetes, and specifically the class Flavobacteria, significantly decreased $(\operatorname{Pr}<0.05)$. While the phylum Proteobacteria did not decrease, both the classes $\alpha$ - and $\beta$-proteobacteria did decrease significantly $(P r<0.05)$. OTUs within the order of Rhizobiales and the family of Rhizobiaceae were significantly decreased by the antibiotic treatments. Shannon's and
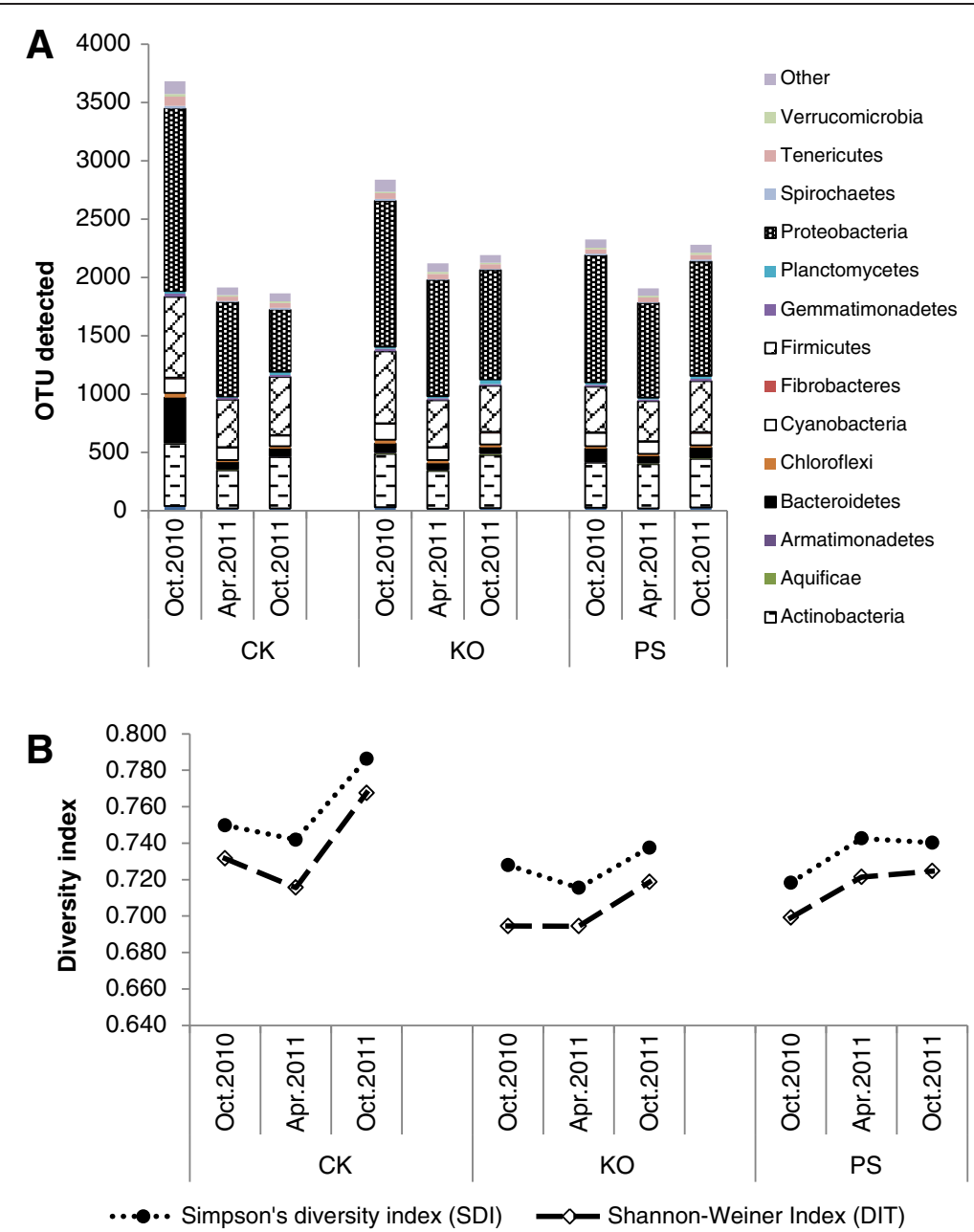

Figure 3 Bacterial richness and diversity in phyla detected by PhyloChip ${ }^{\mathrm{TM}} \mathrm{G} 3$ hybridization of Huanglongbing (HLB)-affected citrus. The citrus plants were treated with different antibiotic combinations, and leaf samples were collected at different times (October 2010, April 2011 and October 2011) over a year. A, Total operational taxonomic units (OTUs) in each treatment; B, Simpson's diversity index (SDI) and ShannonWeiner index (DIT). Each bar represents the coded relative abundance of bacteria in a single phylum. For each treatment, the Simpson's and Shannon's diversity statistics, which reflect both species numbers and evenness of species distribution, were plotted below the histogram. PS: $5 \mathrm{~g} /$ tree penicillin G potassium and $0.5 \mathrm{~g} /$ tree streptomycin; KO: $2 \mathrm{~g} /$ tree oxytetracycline and $1.0 \mathrm{~g} /$ tree kasugamycin; and CK: water as control. 
Simpson's indices both revealed greater diversity in the water control (Figure 3B), indicating that antibiotic treatments lead to lower phylum diversity.

The proportions of OTUs for the most highly represented families (Figure 4) showed a large variation in the number of OTUs detected in the Comamonadaceae, Staphylococcaceae, Corynebacteriaceae, and Flavobacteriaceae families. In accordance with the Las bacterial titers, the amount of OTUs in Comamonadaceae significantly decreased in April 2011 when compared to the other sampling time points (October 2010 and October 2011); however, the amount of OTUs in the Enterobacteriaceae and Aquabacteriaceae families significantly increased.

\section{Specific OTUs associated with the antibiotic treatments and sampling time points}

Principal coordinate analysis (PCoA) based on the weighted Unifrac distances between samples was performed with PhyloChip community data sets, and the results suggested that there were significant differences among the treatments and the sampling time points. The 17 OTUs selected with filter-3, which includes OTUs present in samples from one treatment but not detected in any samples of the other treatments, separated the antibiotic combinations (KO, PS) and the control group (CK). There were eight OTUs $(7444,8217,15010,24693,41872$, 62344, 74687 and 77432) in the KO treatment, three in the PS treatment $(24114,40218$ and 49638$)$ and six in the water control $(42278,50217,53352,58803,70400$ and 75179). When compared with the Antibiotic Resistance

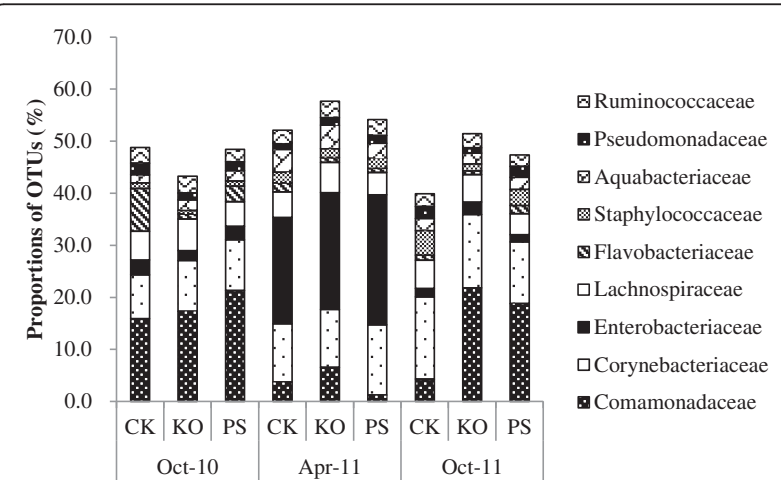

Figure 4 Operational taxonomic units (OTUs) for families detected by PhyloChip ${ }^{\mathrm{TM}} \mathrm{G} 3$ hybridization of Huanglongbing (HLB)-affected citrus. The citrus plants were treated with different antibiotic combinations and leaf samples were collected at different times (October 2010, April 2011 and October 2011) over a year. Proportions of OTUs for the most highly represented families are represented over the sampling time points. The size of each block in the family abundance bar chart represents the number of detected OTUs in that family relative to the total number of OTUs detected with the same treatment over the sampling time points. PS: $5 \mathrm{~g} /$ tree penicillin G potassium and $0.5 \mathrm{~g} /$ tree streptomycin; KO: $2 \mathrm{~g} /$ tree oxytetracycline and $1.0 \mathrm{~g} /$ tree kasugamycin; and CK: water as control.
Genes Database [22], three oxytetracycline-resistant bacteria (7444, 24693 and 72432) were found in the KO treatment (Table 1). No antibiotic-resistant bacteria were found in the PS treatment. Prediction analysis for microarrays (PAM) identified Bacillus OTU48007 within Firmicutes to have increased abundance in the control samples compared to the antibiotic treatments. A total of 118 OTUs with filter-5, based on abundance metrics, partitioned the samples into distinct groups corresponding to sampling time points. Using binary metrics, 344 OTUs selected with filter- 5 were found in $100 \%$ of the samples from one time point and were consistently absent in other time point samples. PAM also identified nine $\gamma$ proteobacterial OTUs (4146, 4198, 4390, 4677, 4739, 5235, 5711, 5749 and 5938) with increased abundance levels in April 2011 samples compared to samples collected in October 2010 and October 2011, and one Sphingomonadaceae, OTU61276, with an increased abundance level in October 2010 (Figure 5).

\section{Discussion}

The high-density $16 \mathrm{~S}$ rRNA gene oligonucleotide microarray, the PhyloChip ${ }^{\text {tw }}$, is employed to study bacterial population diversity, and it is effective for identifying bacteria in the environment $[5,23]$. The PhyloChip ${ }^{\mathrm{Tm}}$ G3 array used in this study contains over 50,000 OTUs representing all demarcated bacterial and archaeal orders [21]. Our results revealed the presence of a total of 7,028 bacterial OTUs in 58 phyla for the field citrus leaf midribs, but no archaea were detected in any of the samples.

The bacterial population of citrus leaves on trees that are asymptomatic for HLB includes Planctomycetes, Verrucomicrobia, Proteobacteria, Actinobacteria, BRC1, Chlamydiae, Chlorobi and Acidobacteria [5], with Proteobacteria being the dominant phylum. In addition to the above mentioned bacteria, other bacteria, including Bacteroidetes and Chloroflexi, have been found in one citrus grove but not in a second grove [5]. Thus, the site appears to influence the composition of the microbial community. In leaves of the evergreen Southern Magnolia tree Proteobacteria were also the most populous bacteria, accounting for $53-80 \%$ of identified $16 \mathrm{~S}$ rRNA gene sequences, followed by Bacteriodetes (11-38\%), Acidobacteria and Actinobacteria [24]. The month of sampling significantly influenced the phylogenetic compositions of the bacterial population, indicating a seasonal fluctuation in bacterial communities [24]. Seasonal variations in the epiphytic populations of bacteria have also been documented in the olive [25]. Thus, there appears to be both spatial and temporal variations in leaf microbial communities.

Citrus leaves can support a variety of microbes. The PhyloChip ${ }^{\text {Tx }}$ analysis in a previous study discovered 47 orders of bacteria in 15 phyla [5]. In our study, 58 phyla 
Table 1 Specific operational taxonomic units (OTUs) detected at all time points in each antibiotic treatment, KO and PS, in the midribs of leaves from Huanglongbing-affected citrus

\begin{tabular}{|c|c|c|c|c|}
\hline $\begin{array}{l}\text { Antibiotic } \\
\text { treatments }\end{array}$ & Specific OTUs & Representative gene & Genus & $\begin{array}{l}\text { Antibiotic-resistant } \\
\text { bacterium }^{z}\end{array}$ \\
\hline \multirow{8}{*}{$\mathrm{KO}$} & 15010 & EF562200.1 & Ralstonia & \\
\hline & 8217 & GQ091863.1 & Diaphorobacter & \\
\hline & 72432 & EU455875.1 & Lactobacillus & Oxy-resistant bacteria \\
\hline & 41872 & AB211018.1 & Thermobifida & \\
\hline & 62344 & AB473971.1 & unclassified & \\
\hline & 24693 & DQ798754.1 & Faecalibacterium & Oxy-resistant bacteria \\
\hline & 74687 & U24588.1 & sfA & \\
\hline & 7444 & NC006370.1 & Photobacterium & Oxy-resistant bacteria \\
\hline \multirow{3}{*}{ PS } & 24114 & EU456745.1 & unclassified & \\
\hline & 49638 & FN356252.1 & unclassified & \\
\hline & 40218 & FJ152555.1 & Isoptericola & \\
\hline \multirow{6}{*}{ CK } & 75179 & AB177144.1 & unclassified & \\
\hline & 53352 & EU381839.1 & Fibrobacter & \\
\hline & 70400 & FJ374203.1 & unclassified & \\
\hline & 42278 & AY660689.1 & unclassified & \\
\hline & 58803 & AB486305.1 & sfA & \\
\hline & 50217 & GQ101329.1 & Veillonella & \\
\hline
\end{tabular}

KO: $2 \mathrm{~g}$ of oxytetracycline $+1.0 \mathrm{~g}$ of kasugamycin per tree.

PS: $5 \mathrm{~g}$ of penicillin $\mathrm{G}$ potassium $+0.5 \mathrm{~g}$ of streptomycin per tree.

CK: water control.

${ }^{\mathrm{Z}}$ Listed in the ARGD (Antibiotic Resistance Genes Database).

were revealed using the Phylochip ${ }^{\text {Tx }}$ G3 array. However, the seasonal variation in the microbial population of citrus has not been extensively studied. The annual fluctuation of endophytic bacteria in Citrus Variegated Chlorosis (CVC) affected citrus showed significant seasonal variations. Yet, as in our study, Proteobacteria was constantly the dominant phylum of bacteria recovered with the $\alpha$-proteobacterial and the $\gamma$-proteobacterial class vying for prevalence. The $\alpha$-proteobacterial class' Methylobacterium spp. was the most populous at three (March-April 1997; September-October 1997; MarchApril 1998) of the four time points and the $\gamma$-proteobacterial class' $P$. agglomerans was the most populous at the final time point (September-October 1998) [26].

The bacterial diversity of HLB-affected citrus leaves was analyzed only once previously using the PhyloChip ${ }^{\text {тм }}$ G2. The bacterial community included Proteobacteria (47.1\%), Bacteroidetes (14.1\%), Actinobacteria (0.3\%), Chlamydiae (0.2\%), Firmicutes $(0.1 \%)$, TM7 (0.05\%), Verrucomicrobia (0.05\%), and Dictyoglomi (0.01\%) [5]. In the present study, we also identified Proteobacteria (38.9\%), Actinobacteria (17.4\%), Bacteroidetes (6.8\%), Verrucomicrobia (0.64\%), and Firmicutes (21.4\%); however, we identified several other phyla (Figure 3A). In the former study the community structure was different between the two groves analyzed; thus, our results from a separate location are not atypical.
Prediction analysis for microarrays (PAM) identified ten $\gamma$-proteobacterial OTUs $(4146,4198,4288,4390$, 4677, 5165, 5711, 5938, 6090 and 6095) with increased abundance levels in the April 2011 samples compared to samples collected in October of 2010 and 2011. The abundance of these OTUs appears to be seasonally driven since there is no statistical difference between samples receiving the water control and the antibiotic treatments. These are all members of the large Enterobacteriaceae family of Gram-negative bacteria. Some members of this family produce endotoxins that reside in the cell cytoplasm and are released upon cell death with the disintegration of the cell wall. The roles of these endophytic bacteria in HLB development remains to be investigated.

To understand the role of Las in HLB progression, it may be important to separate the temporal changes in the microbial community from the changes caused by or associated with HLB. These seasonal changes have been seen not just in the surface phyllosphere but also in the internal tissues as well. Bacterial populations in the xylem undergo temporal variations in shade trees [27]. In grape vines it has been shown that the endophytic community is similar in healthy plants and plants with undetectable levels of phytoplasmas, but it is different in recovered plants [28]. This reorganization of the bacterial community could indicate direct competition between the 


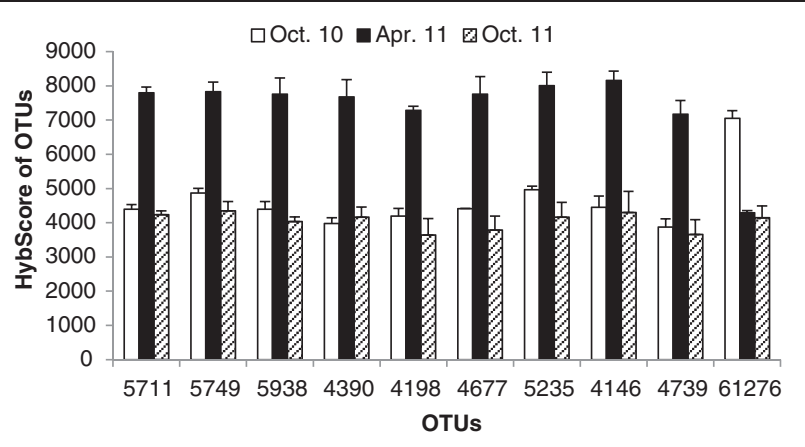

\begin{tabular}{clll}
\multicolumn{1}{l}{ Key: } & & & \\
\hline \multicolumn{1}{c}{ OTUs } & Class & Family & Representative gene \\
\hline 5711 & $\gamma$-proteobacteria & Enterobacteriaceae & EU009185.1 \\
5749 & $\gamma$-proteobacteria & Enterobacteriaceae & EU472747.1 \\
5938 & $\gamma$-proteobacteria & Enterobacteriaceae & AB244457.1 \\
4390 & $\gamma$-proteobacteria & Enterobacteriaceae & EU926632.1 \\
4198 & $\gamma$-proteobacteria & Enterobacteriaceae & GQ047641.1 \\
4677 & $\gamma$-proteobacteria & Enterobacteriaceae & CP001637.1 \\
5235 & $\gamma$-proteobacteria & Enterobacteriaceae & EU470628.1 \\
4146 & $\gamma$-proteobacteria & Enterobacteriaceae & GQ008742.1 \\
4739 & $\gamma$-proteobacteria & Enterobacteriaceae & NC_010498.1 \\
61276 & $\alpha$-proteobacteria & Sphingomonadaceae & EU431820.1 \\
\hline
\end{tabular}

Figure 5 PhyloChip ${ }^{T M}$ G3 HybScore profiles of operational taxonomic units (OTUs) identified by Prediction Analysis for Microarray (PAM). Selected OTUs from leaf samples of Huanglongbing (HLB)-affected citrus treated with different antibiotic combinations at different sampling time points. PAM identified nine Enterobacteriaceae OTUs (OTUs 5711, 5749, 5938, 4390, 4198, 4677, 5235, 4146 and 4739 ) with increased abundance levels in the April 2011 samples when the 'Candidatus Liberibacter asiaticus' (Las) bacterial titers were the lowest compared to samples collected in October of 2010 and 2011, and one Sphingomonadaceae OTU, 61276, with an increased abundance level in October 2010.

infective agent and the endophytic bacteria. It could also be the effect of the plant defense response selecting different strains to adapt to new niches. In addition, the modification of the quantitative levels of some bacteria by the infection could alter the relative bacterial proportions. After antibiotic treatments, Proteobacteria, Firmicutes, Actinobacteria, Bacteroidetes and Cyanobacteria were dominant in the bacterial populations. The Phylochip ${ }^{\mathrm{Ts}}$ G3 indicated that the OTU62086, representing "Candidatus Liberibacter", was detected in all treatments, but had a lower HybScore in the antibiotic treatments, which corresponded with the titers of the Las bacterium. In our previous reports $[17,29,30]$, penicillin alone and its combinations with streptomycin were effective in eliminating or suppressing the Las bacterium in greenhouse plants. In this research, trunk-injections of the antibiotic combinations of penicillin and streptomycin, or kasugamycin and oxytetracycline, suppressed the Las bacterium in HLB-affected citrus in the field throughout the growing season. Las bacterial titers were significantly lower in the PS- or KO-treated HLB-affected trees compared to untreated trees (water control) two months after the initial applications in August $2010(\operatorname{Pr}<0.05)$. The Las bacterial titers increased in the KO-treatment, but remained at a significantly lower level in the PS-treated trees $(\operatorname{Pr}<0.05)$ for two months (October 2011) after the antibiotic treatments ceased in August 2011. A graft-based chemotherapy analysis of streptomycin and kasugamycin, two amnioglycoside antibiotics, revealed that they were not very effective in suppressing the Las bacterium when each antibiotic was applied alone (data not shown). The effectiveness of penicillin or oxytetracycline against the Las bacterium was enhanced due to the use of antibiotic combinations [30]. Because tetracycline is bacteriostatic rather than bactericidal, it is necessary to frequently apply oxytetracycline for continuous suppression of HLB [15,31]. Thus, it is important to use the antibiotics in combination to decrease the emergence of antibiotic resistant bacteria and to improve the efficacy against the bacteria [32]. In this experiment three OTUs were identified, by searching the Antibiotic Resistance Genes Database [22], as oxytetracycline resistant genes but no penicillin resistant genes emerged. This research may assist regulatory agencies in evaluating the potential for applying antibiotic treatments in the future to larger grove settings.

The temporal and antibiotic-dependent significant differences in the bacterial community have implications not only for biocontrol but also for phytopathology. The composition of the bacterial community may strongly influence the establishment of antagonistic 
bacteria at appropriate times during plant development or the growing season. By understanding the composition of, and variation in, the bacterial community of citrus we may be able to time HLB control treatments better and to harness the plants own natural microbial population. This will help establish better management and treatment strategies.

\section{Conclusions}

Using the Phylochip ${ }^{\mathrm{Ts}}$ G3 array, the bacterial composition and community structure in HLB-affected citrus plants during a growing season and while being treated with antibiotic combinations PS and $\mathrm{KO}$ were studied. We identified Proteobacteria as the major phylum in citrus leaf midribs from the USHRL farm in Fort Pierce, FL. While Proteobacteria were the dominant bacteria throughout the growing season, the $\alpha$-proteobacterial and $\beta$-proteobacterial classes decreased significantly $(\operatorname{Pr}<0.05)$ from October 2010 to April 2011 and the $\gamma$-proteobacteria as a class increased $(P r<0.05)$. From April 2011 to October 2011 the $\beta$-proteobacterial class had significantly more OTUs $(\operatorname{Pr}<0.05)$ and the number of OTUs in the $\gamma$ proteobacterial class had decreased significantly $(\operatorname{Pr}<0.05)$. These temporal fluctuations in the bacterial population may affect the microenvironment; thus, making the composition of the microbial community an important factor in the ability of Las to cause HLB progression. Both antibiotic treatments, PS and $\mathrm{KO}$, resulted in decreases in the number of OTUs in the dominant phyla, except Cyanobacteria, and the over-all diversity of bacteria decreased from 7,028 OTUs to 5,599 OTUs by April 2011. The antibiotic treatments resulted in significantly lower Las bacterial titers $(\operatorname{Pr}<0.05)$ and hybridization scores. However, within the Proteobacteria, ten OTUs representing the class $\gamma$-proteobacteria increased in abundance after four months of treatment, when the Las bacterium was at its lowest level in the HLB-affected citrus field plants. Antibiotics altered the taxonomic composition of the bacterial community and reduced their diversity while suppressing the Las bacterium. Our data revealed that Las levels fluctuated temporally, as part of the over-all bacterial population dynamics, and as a response to the antibiotic treatments.

\section{Methods}

\section{Antibiotic treatments on HLB-affected citrus}

The antibiotic treatments were conducted in a randomized complete block design with four replicates. For each replicate, five HLB-affected, 7-year-old citrus trees (a unique hybrid, 10c-5-58, which is an open-pollinated seedling from the combination of Lee mandarin $\times$ Orlando tangelo) at the USHRL farm, $10 \mathrm{~cm}$ in diameter, were injected with either $100 \mathrm{ml}$ of the antibiotic combination treatment PS $(5 \mathrm{~g}$ of penicillin $\mathrm{G}$ potassium $+0.5 \mathrm{~g}$ of Streptomycin per tree) or the antibiotic treatment $\mathrm{KO}$ ( $2 \mathrm{~g}$ of oxytetracycline $+1.0 \mathrm{~g}$ of kasugamycin per tree). Five trees were injected with water as injection controls (CK). Injections were made using an Avo-Ject syringe injector (a catheter-tipped $60 \mathrm{ml}$ syringe; Aongatete Coolstores Ltd., NZ) beginning in August of 2010. The tapered tip was firmly fitted into a 19/64-in $(7.5 \mathrm{~mm})$ diameter hole, $\approx 3 \mathrm{~cm}$ deep, drilled into the tree. The injector was kept in the tree and the treatment lasted for one week in each injection-trunk. Treatments were repeated every two months for one year and ceased in August of 2011. Before and during treatment more than 30 leaf samples per tree were taken from different positions around the tree canopies for qPCR assays at two month intervals.

\section{Genomic DNA extraction and qPCR analysis for the HLB bacterium}

Each leaf sample was rinsed three times with sterile water. Midribs were separated from the leaf samples and cut into pieces of 1.0 to $2.0 \mathrm{~mm}$. DNA was extracted from $0.1 \mathrm{~g}$ of tissue (fresh weight) of leaf midribs using Qiagen's DNeasy Plant Mini Kit (Qiagen, Valencia, CA) according to the manufacturer's protocol. The bacterial titers were quantified by qPCR using the primers and probes (HLBas, HLBr, and HLBp) for ' $\mathrm{C} a$. L. asiaticus' as described previously [17,33]. Data were analyzed by a generalized linear mixed model using the SAS procedure GLIMMIX. Differences among treatments and sampling time points were determined with the LINES option of the LSMEANS statement.

\section{PCR amplification of 16S rRNA genes for PhyloChip ${ }^{\text {TM }}$ G3 hybridization}

DNA for the PhyloChip ${ }^{\mathrm{TM}}$ G3 analysis, which was extracted from 20 samples of the same treatment, was pooled in equal amounts and quantified by the PicoGreen ${ }^{\circ}$ method. The PhyloChip ${ }^{\mathrm{m}}$ G3 analysis was conducted by Second Genome Inc. (San Francisco, CA). The bacterial 16S rRNA genes were amplified from the above pooled DNA using an eight-temperature gradient PCR (annealing temperatures of 48.0, 48.8, 50.1, 51.9, 54.4, 56.3, 57.5, and $58.0^{\circ} \mathrm{C}$ ) with bacterially directed primers $27 \mathrm{~F}$ (5-AGA GTT TGA TCC TGGCTC AG) and 1492R (5-GGT TAC CTT GTT ACG ACT T). In brief, the $25 \mu$ l reactions (final concentrations were $1 \times$ Ex Taq Buffer with $2 \mathrm{mM}$ $\mathrm{MgCl}_{2}, 200 \mathrm{nM}$ each primer (27 $\mathrm{F}$ and 1492R), $200 \mu \mathrm{M}$ each dNTP, $25 \mu \mathrm{g}$ bovine serum albumin (Roche Applied Science, Indianapolis, IN), and 0.625 U Ex Taq (TaKaRa Bio Inc., Shiga, Japan) were amplified using an iCycler (Bio-Rad, Hercules, CA) under the following thermocycling conditions: $95^{\circ} \mathrm{C}$ for $3 \mathrm{~min}$ for initial denaturation, 35 cycles of $95^{\circ} \mathrm{C}$ for $30 \mathrm{~s}, 48$ to $58^{\circ} \mathrm{C}$ for $30 \mathrm{~s}$, and $72^{\circ} \mathrm{C}$ for $2 \mathrm{~min}$, and then final extension for $10 \mathrm{~min}$ at $72^{\circ} \mathrm{C}$. 
PCR products from each annealing temperature for a sample were combined and concentrated using Amicon centrifugal filter units (Millipore Corp., Billerica, MA). The samples were quantified by electrophoresis using an Agilent 2100 Bioanalyzer $^{\circ}$ before application to the PhyloChip $^{\text {tw }}$ G3 array. PhyloChip Control Mix ${ }^{\text {tm }}$ was added to each amplified product.

\section{PhyloChip ${ }^{\mathrm{TM}} \mathrm{G} 3$ hybridization}

About $500 \mathrm{ng}$ of purified PCR product (amplicons) was applied to each PhyloChip ${ }^{\text {ti }}$ G3 following the described procedures [21]. Briefly, the $16 \mathrm{~S}$ rRNA amplicons and a mixture of amplicons at known concentrations were combined, fragmented using DNAseI (Invitrogen, Carlsbad, CA), and biotin-labeled using the recommended protocol for Affymetrix Prokaryotic Arrays. Labeled products were hybridized overnight at $48^{\circ} \mathrm{C}$ and $60 \mathrm{rpm}$. The arrays were washed, stained, and scanned as described in Hazen et al. [21].

\section{Data collection and analysis}

Details on probe selection, probe scoring, data acquisition, and preliminary data analysis are presented in Hazen et al. [21] and the analyses were performed by Second Genome (San Bruno, CA, USA). In brief, two criteria were met when the probe pairs scored as positive: (i) the PM (Perfect Match) probe's intensity of fluorescence was greater than 1.3 times that from the MM (Mismatch) control and (ii) the difference in intensity, PM minus MM, was at least 500 times greater than the squared noise value $\left(>500 \mathrm{~N}^{2}\right)$, which was the variation in pixel intensity signals observed by the scanner as it read the array surface. An OTU was considered present in the sample when over $90 \%$ of its assigned probe pairs were positive. A hybridization intensity score (HybScore) was calculated in arbitrary units for each probe set as the trimmed average (maximum and minimum values removed before averaging) of the PM minus MM intensity differences across the probe pairs in a given probe set. The values of the present OTUs used for each taxa-sample intersection were populated in two distinct ways. In the first case, the abundance metrics were used directly (AT). In the second case, binary metrics were created where 1's represented presence, 0 's indicated absence (BT). OTUs were filtered in several different manners. Filter-1 includes OTUs present in at least one of the samples. Filter-3 includes OTUs present in samples from one treatment but not detected in any samples of the other treatments. Filter-5 includes OTUs whose abundance significantly increased in one treatment compared to the other treatments and Filter-9 includes OTUs with unique abundance patterns within a species. For Filter-3, the percent prevalence required among the samples in one state began at $100 \%$ but then decreased until the OTU set intersected all samples. Thus, each sample contained a present call for at least one of the passing OTUs. The Unifrac distance metric determines the dissimilarity between communities by using the phylogenetic distances between OTUs [34]. For the weighted Unifrac distance metric, WUnifrac, the OTU abundance was also considered. The presence/absence (BT) data, used Unifrac; whereas, the abundance data (AT) used WUnifrac. For Filter-5, p-values were calculated using the parametric Welch test. In this exploratory analysis, false discovery rates were not considered in the p-value calculations. For Filter-9, OTUs were clustered via an average-neighbor (HC-AN) method such that all the OTUs in a group were from the same species and had similar abundance patterns. Abundance patterns were measured by the correlation of abundance vectors across all samples. The max HybScore and min HybScore (the two most variable scores) of OTUs from each treatment were selected and the remaining OTUs were discarded. Principal Coordinate Analysis (PCoA) used the dissimilarity values to position the sample points relative to each other. Significant OTUs, those whose abundance characterized each class, were compiled using Prediction Analysis for Microarrays (PAM) using a nearest shrunken centroid method [35].

\section{Bacterial biodiversity index}

The Shannon and Simpson biodiversity indexes combine both components of species number and their relative abundance [36]. Here they were used to analyze the differences in bacterial diversity among the antibiotic combination treatments calculated from present OTUs as: Shannon's index, $H^{\prime}=-\sum_{1}^{n} P_{i} \operatorname{Ln} P_{i}$, and Simpson's index, $D=\sum_{1}^{n} P_{i}^{2}$. Where n represents the richness or total number of phyla, $P_{i}$ is the proportion of the present OTUs accounted for by the $i^{\text {th }}$ phylum from the total OTUs detected and $L n$ was the natural logarithm.

\section{Availability of supporting data}

The data sets supporting the results of this article are available in the Geo repository, GSE46727 http://www. ncbi.nlm.nih.gov/geo/query/acc.cgi?acc=GSE46727.

\section{Additional file}

Additional file 1: Table S1. Average number of operational taxonomic units (OTUs) detected by PhyloChip ${ }^{\text {TM }} \mathrm{G} 3$ hybridization in the treatments over the sampling time points and in the sampling time points over the treatments from Huanglongbing (HLB)-affected citrus plants treated with different antibiotic combinations. Table of operational taxonomic units (OTUs) in bacterial phyla based on antibiotic treatments and sampling time points.

\section{Competing interests}

The authors declare that they have no competing interests. 


\section{Authors' contributions}

$M Z$, YG and LB carried out the field studies and the DNA extractions. CP and $Y D$ participated in the design of the study and its coordination. $M Z, L B, Y D$ and CP performed the analysis and drafted the manuscript. All authors read and approved the final manuscript.

\section{Acknowledgements}

This work was supported by the Florida Citrus Advanced Technology Program awards 161 and 162 and the Specialty Crop Block Grant 018023 from the Florida Department of Agriculture and Consumer Services. Ms. C. Latza and Mr. G. Brock are greatly appreciated for their excellent technical assistance in the research.

Mention of trade names or commercial products in this publication is solely for the purpose of providing specific information and does not imply recommendation or endorsement by the U.S. Department of Agriculture.

\section{Author details}

'Indian River Research and Education Center, IFAS-UF, Fort Pierce, FL 34945, USA. ${ }^{2}$ USDA-ARS, US Horticultural Lab, Fort Pierce, FL 34945, USA. ${ }^{3}$ State Key Laboratory for Conservation and Utilization of Subtropical Agro-bioresources, Guangxi University, Guangxi 530004, China.

Received: 27 September 2012 Accepted: 20 May 2013 Published: 23 May 2013

\section{References}

1. Hodges AW, Spreen TH: Economic Impacts of Citrus Greening (HLB) in Florida, 2006/7-2010/11, Electronic Data Information Source (EDIS) Update FE903 2012. Gainesville, FL: University of Florida Department of Food and Resource Economics, University of Florida [http://news.ufledu/2012/01/24/greening-cost]

2. Bové JM: Huanglongbing: a destructive, newly-emerging, century-old disease of citrus. J Plant Pathol 2006, 88(1):7-37.

3. National Research Council of the National Academies: Strategic Planning for the Florida Citrus Industry: Addressing Citrus Greening. Washington, D.C: National Academies Press; 2010

4. Lindow SE, Brandl MT: Microbiology of the phyllosphere. App Env Micro 2003, 69(4):1875-1883.

5. Sagaram U, DeAngelis KM, Trivedi P, Andersen GL, Lu SE, Wang N: Bacterial diversity analysis of huanglongbing pathogen-infected citrus, using PhyloChip arrays and 16S rRNA gene clone library sequencing. Appl Env Micro 2009, 75:1566-1574.

6. Trivedi P, Duan YP, Wang N: Huanglongbing, a systemic disease, restructures the bacterial community associated with citrus roots. Appl Env Micro 2010, 76(11):3427-3436.

7. Thirmalachar MJ: Antibiotics in the control of plant pathogens. Adv Appl Micro 1968, 10:313-337.

8. McManus PS: Antibiotic use in plant disease control. APUA Newsletter 1999, 17(1):1-3.

9. McManus PS, Stockwell VO, Sundin GW, Jones AL: Antibiotic use in plant agriculture. Ann Rev Phyto 2002, 40:443-465.

10. McManus PS, Stockwell VO: Antibiotic use for plant disease management in the United States. Plant Health Prog 2001. doi:10.1094/PHP-2001-0327-01-RV.

11. Le Roux HF, van Vuuren SP, Pretorius MC, Buitendag CH: Management of huanglongbing in South Africa. In Proc Huanglongbing-Greening Intl Workshop 2006. Ribeirão, S.P. Brazil; 2006:43-47.

12. Su HJ, Chang SC: Electron microscopical study on the heat and tetracycline response, and ultra-structure of the pathogen complex causing citrus likubin disease. In Proc 8th Int Congr Electron Microscopy 1974. 2nd edition. Canberra, Australia: The Australian Acad of Sci; 1974:628-629.

13. Chiu RJ, Tsai MY, Huang CH: Distribution of retention of tetracycline in healthy and likubin infected citrus trees following trunk transfusion. In Proc ROC-US Coop Sci Seminar on Mycoplasma Diseases of Plants, Volume Ser 1. Edited by Su HJ, McCoy RE. Taipei, Taiwan: National Science Council Symposium; 1979:43-152

14. Supriyanto A, Whittle AM: Citrus rehabilitation in Indonesia. In Proc 11th Conf Int Org Citrus Virologists 1991. Riverside, CA: IOCV; 1991:409-413.

15. Abdullah TL, Shokrollah H, Sijam K, Abdullah SNA: Control of huanglongbing $(\mathrm{HLB})$ disease with reference to its occurrence in Malaysia. Afr JBiotechnol 2009, 8(17):4007-4015.

16. Cheema SS, Kapur SP, Sharma OP: Chemo-therapeutic controls of greening disease of citrus through bud dip treatment. Indian J Virol 1986, 2:104-107.
17. Zhang MQ, Powell CA, Zhou LJ, He ZL, Stover E, Duan YP: Chemical compounds effective against the citrus huanglongbing bacterium 'candidatus liberibacter asiaticus' in planta. Phyto 2011, 101:1097-1103.

18. Vasileiadis S, Puglisi E, Arena M, Cappa F, Cocconcelli PS, Tregisan M: Soil bacterial diversity screening using single $16 \mathrm{~S}$ rRNA gene $\mathrm{V}$ regions coupled with multi-million read generating sequencing technologies. PLoS One 2012, 7(8):e42671. doi:10.1371/journal.pone.0042671.

19. Gurdeep R, Rajesh KS: Molecular Techniques to Assess Microbial Community Structure, Function, and Dynamics in the Environment. In Microbes and Microbial Technology: Agricultural and Environmental Applications. Edited by Ahmad I, Ahmad F, Pichtel J. New York: Springer; 2011:29-57.

20. Wilson KH, Wilson WJ, Radosevich JL, DeSantis TZ, Viswanathan VS, Kuczmarski TA, Andersen GL: High-density microarray of small-subunit ribosomal DNA probes. Appl Env Micro 2002, 68:2535-2541.

21. Hazen TC, Dubinsky EA, DeSantis TZ, Andersen GL, Piceno YM, Singh N, Jansson JK, Probst A, Borglin SE, Fortney JL, Stringfellow WT, Bill M, Conrad ME, Tom LM, Chavarria KL, Alusi TR, Lamendella R, Joyner DC, Spier C, Baelum J, Auer M, Zemla ML, Chakraborty R, Sonnenthal EL, D'haeseleer P, Holman HY, Osman S, Lu Z, Van Nostrand JD, Deng Y, et al: Deep-sea oil plume enriches indigenous oil degrading bacteria. Science 2010, 330:204-208.

22. Liu B, Pop M: ARDB-Antibiotic Resistance Genes Database. Nuc Acids Res 2009, 37. (Database issue):D443-7. [http://ardb.cbcb.umd.edu/]

23. Brodie EL, DeSantis TZ, Joyner DC, Baek SM, Larsen JT, Andersen GL, Hazen TC, Richardson PM, Herman DJ, Tokunaga TK, Wan JMM, Firestone MK: Application of a high-density oligonucleotide microarray approach to study bacterial population dynamics during uranium reduction and reoxidation. Appl Env Micro 2006, 72:6288-6298.

24. Jackson CR, Denney WC: Annual and seasonal variation in the phyllosphere bacterial community associated with leaves of the southern magnolia (magnolia grandiflora). Plant Micro Interactions 2010, 61:113-122.

25. Ercolani GL: Pseudomonas savastanoi and other bacteria colonizing the surface of olive leaves in the field. J Gen Micro 1978, 109:245-257.

26. Araújo WL, Marcon J, Maccheroni W Jr, van Elsas JD, van Vuurder JWL, Azevedo $J \mathrm{~L}$ : Diversity of endophytic bacterial populations and their interaction with xylella fastidiosa in citrus plants. App Env Micro 2002, 68(10):4906-4914.

27. Gould AB, Lashomb JH: Bacterial leaf scorch (BLS) of shade trees. The Plant Health Instructor 2007. doi:10.1094/PHII--2007-0403-07.

28. Bulgari D, Casati P, Crepaldi P, Daffonchio D, Quaglino F, Brusetti L, Bianco PA: Restructuring of endophytic bacterial communities in grapevine yellowsdiseased and recovered vitis vinifera L. Plants. App Env Micro 2011, 14:5018-5022.

29. Zhang MQ, Duan YP, Zhou LJ, Turechek WW, Stover E, Powell CA: Screening molecules for control of citrus huanglongbing using an optimized regeneration system for 'candidatus liberibacter asiaticus'-infected periwinkle (catharanthus roseus) cuttings. Phyto 2010, 100:239-245.

30. Zhang MQ, Powell CA, Guo Y, Doud MS, Duan YP: A graft-based chemotherapy method for screening effective molecules and rescuing huanglongbing-affected citrus plants. Phyto 2012, 102:567-574.

31. Schwarz RE, Van Vuuren SP: Decrease in fruit greening of sweet orange by trunk injection of tetracycline. Plant Dis Rep 1971, 55:747-750.

32. MCManus PS, Jones AL: Epidemiology and genetic analysis of streptomycin-resistant erwinia amylovora from Michigan and evaluation of oxytetracycline for control. Phyto 1994, 84:627-633.

33. Li WB, Hartung JS, Levy L: Optimized quantification of unculturable 'candidatus liberibacter spp'. In host plants using real-time PCR. Plant Dis 2008, 92:854-861.

34. Lozupone C, Lladser ME, Knights D, Stombaugh J, Knight R: UniFrac: an effective distance metric for microbial community comparison. ISME J 2011, 5(2):169-172.

35. Tibshirani R, Hastie T, Narasimhan B, Chu G: Diagnosis of multiple cancer types by shrunken centroids of gene expression. PNAS 2002, 99(10):6567-6572.

36. Laura PLA: Bootstrap confidence intervals for the Shannon biodiversity index: a simulation study. J Agric Biol Environ Stat 2004, 9:42-56.

doi:10.1186/1471-2180-13-112

Cite this article as: Zhang et al:: Characterization of the microbial community structure in Candidatus Liberibacter asiaticus-infected citrus plants treated with antibiotics in the field. BMC Microbiology 2013 13:112. 